\title{
A study on prevalence of anemia in pregnancy in South India
}

\author{
Sarala V., Ushadevi Gopalan*
}

Department of Obstetrics and Gynecology, Shri Sathya Sai Medical College and Research Institute, Ammapettai Village, Kancheepuram District, Tamil Nadu, India

Received: 14 November 2019

Revised: 20 November 2019

Accepted: 25 November 2019

\section{*Correspondence:}

Dr. Ushadevi Gopalan,

E-mail: ushag7@hotmail.com

Copyright: $@$ ( the author(s), publisher and licensee Medip Academy. This is an open-access article distributed under the terms of the Creative Commons Attribution Non-Commercial License, which permits unrestricted non-commercial use, distribution, and reproduction in any medium, provided the original work is properly cited.

\section{ABSTRACT}

Background: Anemia in pregnancy is a major health problem worldwide, especially in developing countries like India. Maternal and fetal outcomes are poor in pregnant patients with anemia. The most important cause of anemia is iron deficiency anemia which can be prevented by early oral iron supplementation.

Methods: This cross-sectional study was conducted in the department of obstetrics and gynecology of our tertiary care teaching institution for a period of one year. 1290 pregnant women coming to the antenatal OPD were screened for anemia and 490 women. Patients who were not anemic were excluded. 800 patients were enrolled in the study. Each patient was interviewed using a structured interview schedule and the data obtained was analyzed.

Results: The percentage of anemia in pregnant women was $62 \%$ in our study of which $40 \%$ were mildly anemic, $55 \%$ were moderately anemic and 5\% were severely anemic. Maximum number of anemic women -mild, moderate and severe was seen in the age group 20-24 years. Mild and severe anemia was seen more in the secondary educated women. Maximum percentage of anemia was seen in the lower socio-economic status followed by middle and was lowest in the higher socio-economic status group. Prevalence of anemia was almost equal in primigravida and multigravidas (around $50 \%$ ) but $80 \%$ of severely anemic patients were multigravida. Almost $68 \%$ took iron and folic acid tablets regularly.

Conclusions: Treating anemia in pregnant women will go a long way in improving maternal and fetal outcome. Hence a future healthy younger generation can be produced. Iron tablets can be distributed at school to young girls to prevent anemia in future women.

Keywords: Anemia, Hemoglobin, Iron supplementation, Maternal mortality

\section{INTRODUCTION}

Anemia during pregnancy is a major health problem in South Asian countries and developing countries. ${ }^{1}$ It is still more prevalent in India. Sowmya $\mathrm{G}$ et al, in their study found the prevalence of anemia in pregnancy as $64.5 \% .^{2}$ Maternal deaths are more in antenatal patients suffering from anemia than healthy mothers. The fetal outcome is also poor with increased perinatal morbidity and mortality. ${ }^{3}$ Anemia is the most common medical disorder during pregnancy. The oxygen carrying capacity of the blood is reduced in anemic patients. The most important cause of anemia is nutritional. More than $70 \%$ of pregnant women suffer from nutritional anemia in South East Asia. ${ }^{4}$ This can be overcome by early oral iron therapy because the most common type of anemia is iron deficiency anemia (75\%). ${ }^{5,6}$ This is mainly due to lack of knowledge regarding the importance of nutrition on maternal health, and poverty inhibits them from buying healthy nutritious food. ${ }^{7,8}$ The aim of the present study is to find out the prevalence of anemia and analyze the distribution of the age, education, socio economic status 
and parity in pregnant anemic women and their acceptance of oral iron therapy.

\section{METHODS}

This cross-sectional study was conducted in the department of obstetrics and gynecology of our tertiary care teaching institution for a period of one year between January 2018 to December 2018. A total 1290 pregnant women coming to our antenatal OPD were screened for anemia using laboratory tests and 490 women who were not anemic were excluded. A total 800 patients were enrolled in the study.

\section{Inclusion criteria}

- Pregnant women

- $\mathrm{Hb} \%$ less than $11 \mathrm{gm} \%$.

\section{Exclusion criteria}

- Non pregnant women

- $\mathrm{HB}$ above $11 \mathrm{gm} \%$.

\section{Study population}

Pregnant women attending the antenatal OPD of our tertiary teaching institution between the ages of 18 to 50 years from nearby villages in Kancheepuram district were considered.

- Total no. of AN Women - 1290

- No. of anemic patient - 800

- Percent of anemic patient $-62 \%$.

Approval was obtained from the Institutional Ethics Committee prior to the commencement of the study. Each participant was explained in detail about the study and written informed consent was obtained prior to the data collection. Each patient was interviewed using a structured interview schedule to obtain information regarding the age, parity, educational and socio-economic status. The severity of anemia was estimated and the intake of iron supplementation by the pregnant patient was also studied.

\section{Statistical analysis}

The data obtained was organized according to the severity of anemia Data was entered and analyzed using Microsoft Excel spreadsheet, and the various degrees of anemia were expressed in percentage.

\section{RESULTS}

Out of 1290 OPD pregnant women 490 had $\mathrm{Hb} \%$ above $11 \mathrm{gm} / \mathrm{dl}$. So, the prevalence of anemia was $62 \%$ of which $40 \%$ were mildly anemic (Hb-9-11 gm\%), 55\% were moderately anemic (Hb-7-9 gm\%) and 5\% were severely anemic (Hb-less than $7 \mathrm{gm} \%$ ) according to WHO classification (Figure 1).

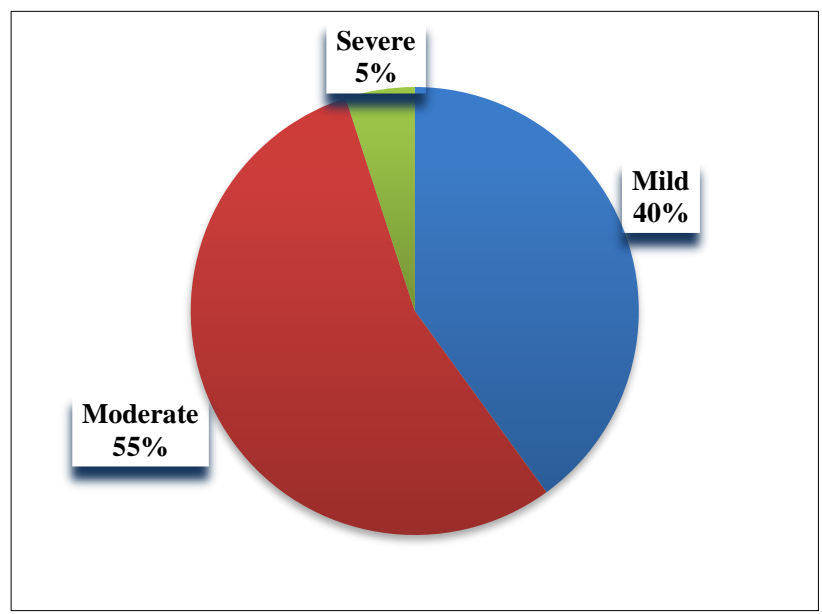

Figure 1: Prevalence of anaemia among pregnant women.

Table 1: Age distribution.

\begin{tabular}{|lllll|}
\hline Age & Mild anemia & Moderate anemia & Severe anemia & Total \\
\hline$<20$ years & $35(10.9 \%)$ & $63(14.3 \%)$ & $6(15 \%)$ & $104(13 \%)$ \\
\hline $20-24$ & $150(47 \%)$ & $320(72.73 \%)$ & $24(60 \%)$ & $494(61.75 \%)$ \\
\hline $25-29$ & $125(39 \%)$ & $44(10 \%)$ & $8(20 \%)$ & $177(22.12 \%)$ \\
\hline$>30$ & $10(3.1 \%)$ & $13(2.95 \%)$ & $2(5 \%)$ & $25(3.72 \%)$ \\
\hline Total & $\mathbf{3 2 0}$ & $\mathbf{4 4 0}$ & $\mathbf{4 0}$ & $\mathbf{8 0 0}$ \\
\hline
\end{tabular}

The 800 anemic women were included in the study. Mean age of the participants was $22.6 \%$. Maximum numbers of anemic women were in the age group 20-24 years (61.75\%) followed by $22.1 \%$ in $25-29$ years and $13 \%$ in less than 20 years group. The least anemia was seen in the age group more than 30 years $(3.72 \%)$ (Table 1$)$. Of the antenatal women $11.5 \%$ were illiterate, primary and secondary educated $36.5 \%$ and $44.75 \%$ respectively and $7.25 \%$ were graduate and above. Anemia was seen more in the secondary educated women $(44.75 \%)$ followed by primary educated women $(36.5 \%)$ and illiterate $(11.5 \%)$. Least percentage of anemias was seen in the graduate 
women $(7.25 \%)$ (Table 2$)$. On analyzing socio-economic status as expected maximum percentage of anemia was seen in the lower socio-economic status $(63.75 \%)$ followed by middle $(32.625 \%)$ and was lowest in the higher socio-economic status group (3.625\%) (Table 3).
Prevalence of anemia in primigravida (49.25\%) and multigravida $(50.75 \%)$ were almost equal but $80 \%$ of severely anemic patients were multigravida. (Table 4). Almost $68 \%$ took iron and folic acid tablets regularly (Table 5).

Table 2: Educational status.

\begin{tabular}{|lllll|}
\hline Education & Mild anemia & Moderate anemia & Severe anemia & Total \\
\hline Illiterate & $48(15 \%)$ & $40(9 \%)$ & $4(10 \%)$ & $92(11.5 \%)$ \\
\hline Primary & $64(20 \%)$ & $218(49.5 \%)$ & $10(25 \%)$ & $292(36.5 \%)$ \\
\hline Secondary & $176(55 \%)$ & $160(36.36 \%)$ & $22(55 \%)$ & $358(44.75 \%)$ \\
\hline Graduate / PG & $32(10 \%)$ & $22(5 \%)$ & $4(10 \%)$ & $58(7.25 \%)$ \\
\hline Total & $\mathbf{3 2 0}$ & $\mathbf{4 4 0}$ & $\mathbf{4 0}$ & $\mathbf{8 0 0}(\mathbf{1 0 0 \%})$ \\
\hline
\end{tabular}

Table 3: Socio economic status.

\begin{tabular}{|lllll|}
\hline Status & Mild anemia & Moderate anemia & Severe anemia & Total \\
\hline Low & $192(60 \%)$ & $286(65 \%)$ & $32(80 \%)$ & $510(63.75 \%)$ \\
\hline Middle & $106(33.1 \%)$ & $149(33.86 \%)$ & $6(15 \%)$ & $261(32.625 \%)$ \\
\hline High & $22(69 \%)$ & $5(1.14 \%)$ & $3(5 \%)$ & $29(3.625 \%)$ \\
\hline Total & $\mathbf{3 2 0}$ & $\mathbf{4 4 0}$ & $\mathbf{4 0}$ & $\mathbf{8 0 0}(\mathbf{1 0 0 \%})$ \\
\hline
\end{tabular}

Table 4: Parity.

\begin{tabular}{|lllll|}
\hline Parity & Mild anemia & Moderate anemia & Severe anemia & Total \\
\hline Primi Para & $162(50.6 \%)$ & $224(50.9 \%)$ & $8(20 \%)$ & $394(49.25 \%)$ \\
\hline Multi Para & $158(49.4 \%)$ & $216(49 \%)$ & $32(80 \%)$ & $406(50.75 \%)$ \\
\hline Total & $\mathbf{3 2 0}$ & $\mathbf{4 4 0}$ & $\mathbf{4 0}$ & $\mathbf{8 0 0}(\mathbf{1 0 0 \%})$ \\
\hline
\end{tabular}

Table 5: Iron supplementation.

\begin{tabular}{|lllll|}
\hline Iron tab consumption & Mild & Moderate & Severe & Total \\
\hline Yes & $256(80 \%)$ & $264(60 \%)$ & $24(60 \%)$ & $544(68 \%)$ \\
\hline No & $64(20 \%)$ & $176(40 \%)$ & $16(40 \%)$ & $256(32 \%)$ \\
\hline Total & $\mathbf{3 2 0}$ & $\mathbf{4 4 0}$ & $\mathbf{4 0}$ & $\mathbf{8 0 0}(\mathbf{1 0 0 \%})$ \\
\hline
\end{tabular}

\section{DISCUSSION}

In this present study, the percentage and severity of anemia in pregnant women was analyzed. The prevalence of anemia in pregnancy in our study was 62\%. The severity of anemia was graded as per WHO classification of anemia. $40 \%$ of the women were mildly anemic, $55 \%$ were moderately anemic and $5 \%$ severely anemic. Similar, results were obtained by Singh $\mathrm{P}$ et al. ${ }^{1}$ As per our study, anemia was most prevalent in age 20-24 years old $(61.75 \%)$. This finding is almost the same as Gaurah et al $(77.9 \%)$ and Shwetha et al $(70 \%) .{ }^{9,10}$ Regarding educational qualification anemia was more prevalent in primary and secondary educational level, $36.5 \%$ and $44.75 \%$ respectively. In our study of socio-economic status, anemia was more common in lower strata of women $(63.75 \%)$. This finding correlates with that of Ahmad $\mathrm{N}$ et al. ${ }^{11}$ Comparing primigravida with multigravida women, anemia is almost equally distributed among both $(50.75 \%)$. In studies by Bison et al and Sowmya et al, they have also reported the same distribution $(50 \%))^{2,12}$ All anemic patients were given iron supplements oral or parenteral. Only $68 \%$ took the treatment continuously (Table 5). Rest of them discontinued at different periods.

\section{CONCLUSION}

Treating anemia in pregnant women will go a long way in improving maternal and fetal outcome. Hence a future healthy younger generation can be produced. Iron tablets can be distributed at school to young girls to prevent anemia in future women. Educating young girls regarding hygiene, nutritious diet, iron supplement even in pre pregnancy stage will prevent anemia to a great extent during pregnancy. 
Funding: No funding sources

Conflict of interest: None declared

Ethical approval: The study was approved by the

Institutional Ethics Committee

\section{REFERENCES}

1. Singh $\mathrm{P}$, Khan S, Mittal RK. Anemia during pregnancy in women of Western Nepal. Bali Med J. 2013;2(1):14-6.

2. Sowmya G, Dhananya BS, Kakarla S, Chandana K. Prevalence of anemia in pregnancy and its outcome in rural tertiary care centre in India. Indian J Obstet Gynaecol Res. 2018;5(1):104-8.

3. Florentine RF. The burden of iron deficiency and anemia in Asia: Challenges in prevention and control. Nutritional Goals for Asia-Vision 2020: Proceedings IX Asian Congress of Nutrition. New Delhi, Nutrition Foundation of India; 2003:313-318.

4. Ian Donald's Practical Obstetric Problems; $6^{\text {th }}$ Ed. 148.

5. Park K. Park textbook of preventive and social medicine by K Park. Iron deficiency anemia: Jabalpur: M/S Banarsidas Bhanot, 21 ${ }^{\text {st }}$ edition' 2013: 575.

6. Siteti CM. Anemia in pregnancy: prevalence and possible risk factors in Kakamega County, Kenya. Sci J Public Health. 2014;2:216.

7. McLean E, Cogswell M, Egli I, Wojdyla D, de Benoist B. Worldwide prevalence of anemia, WHO vitamin and mineral nutrition information system, 1993-2005. Public Health Nutr. 2009;12:444-547.

8. Goli S, Rammohan A, Singh D. The effect of early marriages and early childbearing on women's nutritional status in India. Matern Child Health J. 2015:19:1700-7.

9. Gourah RT, Anand A. To study the efficacy, safety and compliance of iron sucrose in mild, moderate and severe anaemia in antenatal patient. Indian $\mathbf{J}$ Obstet Gynaecol Res. 2017;4(4):350-5.

10. Shwetha P. Prevalence of anemia among pregnant women: A cross-sectional study. Int J Med Sci Pub Health. 2018;7(12):1023-7.

11. Ahmad N, Kalakoti P, Bano R, Syed MMA. The prevalence of anemia and associated factors in pregnant women in a rural Indian community. AMJ. 2010;3(5):276-80.

12. Bisoi S, Haldar D, Majundar TK, Bhattacharya N, Sarkar GN, Ray SK. Correlates of anaemia among pregnant women in a rural area of West Bengal. The J Fam Welfare. 2013;57(1):72-8.

Cite this article as: Sarala V, Gopalan U. A study on prevalence of anemia in pregnancy in South India. Int J Reprod Contracept Obstet Gynecol 2020;9:34-7. 